\title{
Real-world Treatment Patterns in Patients with EGFR Mutation-positive NSCLC Receiving a First-Line, First- or Second-generation EGFR Tyrosine Kinase Inhibitor in South Korea and Taiwan
}

\author{
Jae Cheol Lee', Jen-Yu Hung,3, Young-Chul Kim, Gee-Chen Chang5,6, Seung \\ Soo Yoo ${ }^{7}$, Sheng-Hsiung Yang ${ }^{8}$, Keith L Davis ${ }^{9}$, Saurabh P Nagar ${ }^{9}$, Aliki Taylor ${ }^{10}$, \\ Sung Yong Lee ${ }^{11}$, Jin-Yuan Shih ${ }^{12}$
}

\begin{abstract}
${ }^{1}$ Department of Oncology, Asan Medical Center, University of Ulsan, College of Medicine, Seoul, Korea. ${ }^{2}$ Division of Pulmonary and Critical Care Medicine, Department of Internal Medicine, Kaohsiung Medical University Hospital, Kaohsiung Medical University, Kaohsiung, Taiwan. ${ }^{3}$ Department of Internal Medicine, Kaohsiung Municipal Ta-Tung Hospital, Kaohsiung, Taiwan. ${ }^{4}$ Department of Internal Medicine, Chonnam National University Medical School and Lung Cancer Clinic, Pulmonary Medicine, Chonnam National University Hwasun Hospital, Jeonnam, Korea. ${ }^{5}$ Division of Chest Medicine, Department of Internal Medicine, Taichung Veterans General Hospital, Taichung, Taiwan. ${ }^{6}$ Faculty of Medicine, School of Medicine, National Yang-Ming University, Taipei, Taiwan. ${ }^{7}$ Lung Cancer Center, Kyungpook National University Chilgok Hospital, Daegu, Korea. ${ }^{8}$ Mackay Memorial Hospital, Taipei, Taiwan. ${ }^{9}$ Health Economics Group, RTI Health Solutions, Research Triangle Park, Durham, NC, USA. ${ }^{10}$ Oncology Business Unit, AstraZeneca, Cambridge, UK. ${ }^{11}$ Pulmonology, Allergy and Critical Care Medicine, Korea University Guro Hospital, Seoul, Korea. ${ }^{12}$ Division of Pulmonary and Critical Care Medicine, National Taiwan University Hospital, Taipei, Taiwan.
\end{abstract}

\begin{abstract}
Introduction: The preferred first-line (1L) treatment for epidermal growth factor receptor (EGFR) mutation-positive (EGFRm) advanced/metastatic non-small lung cancer (NSCLC) are EGFR-tyrosine kinase inhibitors (TKIs). However, most patients treated with $1 \mathrm{~L}$ first- or second-generation $(1 \mathrm{G} / 2 \mathrm{G})$ EGFR-TKIs acquire resistance; the EGFR T790M mutation is observed in $\sim 30-50 \%$ of patients. We report real-world NSCLC treatment and T790M testing patterns in South Korea and Taiwan. Methods: Retrospective medical record review of EGFRm advanced/metastatic NSCLC patients from routine practice. 1G/2G EGFR-TKI initiation 1 January 2015-31 December 2017 (follow-up end date: last available medical record or August 2019). Study measures: demographic/disease characteristics, 1L/2L treatment, T790M testing. Results: In South Korea, 70\% (164/235) and in Taiwan 89\% (89/100) experienced 1L disease progression (median [range] follow-up: 22 [2.3-50.7] months). Of those with disease progression, 68\% (111/164) and 62\% (55/89) had T790M testing in South Korea and Taiwan, respectively. In South Korea, 43\% (48/111) were T790M-positive with 88\% (n=42/48) receiving osimertinib (mostly 2L). In Taiwan, 18\% (10/55) were T790M-positive; $100 \%$ received osimertinib. Overall, $73 \%(120 / 164)$ and $63 \%(63 / 100)$ in South Korea and Taiwan, respectively, received $2 \mathrm{~L}$ therapy, predominantly pemetrexed-containing regimens. Among patients with disease progression, 9\% (14/164) and 24\% (21/89) died before receiving $2 \mathrm{~L}$ therapy in South Korea and Taiwan, respectively. Conclusion: In both countries, $<70 \%$ with $1 \mathrm{~L}$ disease progression were tested for T790M at any point from NSCLC diagnosis, suggesting resistance mutation testing could be improved. Treatment/testing patterns may have changed in both countries since study initiation due to osimertinib reimbursement changes beginning December 2017.
\end{abstract}

Keywords: EGFR mutation- EGFR-TKI- NSCLC- osimertinib- T790M

Asian Pac J Cancer Biol, 6 (2), 123-132

Submission Date: 03/18/2021 Acceptance Date: 04/26/2021

\footnotetext{
Corresponding Author:

Professor. Jae Cheol Lee

Asan Medical Center, Seoul, Korea.

Email: jclee@amc.seoul.kr
} 


\section{Introduction}

Epidermal growth factor receptor (EGFR) mutations (EGFRm) are observed in a greater proportion of patients with non-small cell lung cancer (NSCLC) from Asian populations (32-60\%) compared with non-Asian populations (10-30\%) [1-3]. In addition, the prevalence of EGFRm in patients with NSCLC from South Korea and Taiwan has been reported to range from 27-51\% [4-6] and 34-53\% [7-9], respectively.

At the time of this study (2015-2017), guidelines recommended first-line (1L) treatment of EGFRm advanced NSCLC with first- or second-generation (1G/2G) EGFR-tyrosine kinase inhibitors (TKIs) erlotinib, gefitinib or afatinib [10-11]. Despite initial efficacy, most patients with EGFRm advanced or metastatic NSCLC treated with a $1 \mathrm{~L} 1 \mathrm{G} / 2 \mathrm{G}$ EGFR-TKI develop resistance, with disease progression occurring after a median of 8 to 16 months [12-14]. The EGFR T790M acquired resistance mutation has been observed in approximately $50 \%$ of patients from a meta-analysis of clinical trials [15] while rates of approximately $30 \%$ have been reported in real-world studies [16-18].

Osimertinib is a third-generation, irreversible EGFR-TKI that potently and selectively inhibits both EGFR-TKI sensitizing and EGFR T790M resistance mutations, and has demonstrated efficacy in NSCLC central nervous system (CNS) metastases [19-22]. Following the Phase III AURA3 study, in November 2015 osimertinib received accelerated approval from the US Food and Drug Administration (FDA) and the European Medicines Agency for use as a second-line (2L) treatment in patients with EGFRm T790M-positive locally advanced or metastatic NSCLC who had previously received $1 \mathrm{G} / 2 \mathrm{G}$ EGFR TKIs. Approval was received in Taiwan and South Korea in March and May 2017, respectively [23-24]. Following approval, the Ministry of Health and Welfare in South Korea granted reimbursement for osimertinib in the 2L setting in December 2017 [23]. In Taiwan, reimbursement for osimertinib in the $2 \mathrm{~L}$ setting was granted in April 2020 [25]. Testing of tumors for T790M in patients with resistance to $1 \mathrm{G} / 2 \mathrm{G}$ EGFR-TKIs in the $1 \mathrm{~L}$ setting is now mandatory, with osimertinib considered the standard of care for patients with T790M-positive tumors [26].

Based on the results of the Phase III FLAURA study, in 2018 osimertinib received approval as a 1L treatment for patients with metastatic NSCLC whose tumors harbored EGFR-TKI sensitizing mutations (exon 19 deletion [Ex19del] or L858R) [27-28]. In line with this, the current Pan Asian guidelines from 2019 now recommend 1L treatment with EGFR-TKIs, including osimertinib, for patients with metastatic NSCLC with tumors harboring an EGFR-TKI sensitizing mutation [26].

While the use of $1 \mathrm{~L} 1 \mathrm{G} / 2 \mathrm{G}$ EGFR-TKIs in patients with EGFRm locally advanced or metastatic NSCLC was well defined at the time of this study, published real-world data for treatment of these patients following NSCLC disease progression are limited in South Korea and Taiwan. This study was designed to review the real-world treatment patterns and T790M testing practices of patients in these settings.

\section{Materials and Methods}

\section{Study Design and Data Source}

This was a retrospective, non-interventional medical record review in selected patients with EGFRm NSCLC from routine clinical practice settings in France, Germany, South Korea, Taiwan, UK and US; here, we describe results from South Korea and Taiwan and data from France, Germany, UK and US are described elsewhere.

Following appropriate ethics submissions and approvals, data were obtained through the use of an electronic data collection form (eDCF), which was completed by physicians or delegated clinical research staff, from medical record reviews of eligible patients. The forms were accessed via a secure web-based link specific to each site and records for each patient in the analytic dataset were then linked by an encrypted identifier. The study was performed in accordance with ethical principles that are consistent with the Declaration of Helsinki, International Conference on Harmonization Good Clinical Practices and local standards in South Korea and Taiwan. Patient consent was not required because of the retrospective nature of the study.

\section{Study population}

\section{Physicians}

Physicians participating in the study were required to have treated $\geq 4$ patients with EGFRm NSCLC in the year preceding the study, $\geq 2$ years' experience in medical practice managing oncology treatment including responsibility for making treatment decision for patients with NSCLC, and to have spent $\geq 60 \%$ of their time in patient care (as judged by the participating physician).

\section{Patients}

Records for adults $\geq 20$ years of age at first diagnosis of confirmed EGFRm locally advanced unresectable or metastatic NSCLC, who had received $1 \mathrm{~L} 1 \mathrm{G} / 2 \mathrm{G}$ EGFRTKI treatment were included; at the time of medical record abstraction, patients could have been alive or deceased. 1L EGFR-TKI treatment (afatinib, gefitinib, erlotinib) must have been initiated between January 12015 and December 31 2017. Patient data were not included if they had previously been enrolled in an interventional clinical trial for an EGFRm NSCLC-related treatment or received any systemic therapy for locally advanced or metastatic NSCLC prior to 1L EGFR-TKI treatment. Patient data were also excluded if there were missing or unknown dates for: initial NSCLC diagnosis, first diagnosis of progression to advanced or metastatic NSCLC, 1L EGFRTKI initiation for advanced or metastatic disease, death, or last available follow-up.

\section{Objectives}

The objectives of the study included describing patients' demographic and baseline disease characteristics; 
the proportion of patients that had, or went on to develop CNS metastases (diagnosis: tissue biopsy, imaging, spinal tap, neurologic exam) or leptomeningeal disease (LM; diagnosis: cerebrospinal fluid cytology, tissue, imaging); 1L EGFR-TKI type used; and the proportion of patients that experienced disease progression on $1 \mathrm{~L} 1 \mathrm{G} / 2 \mathrm{G}$ EGFR-TKIs. In patients with disease progression on $1 \mathrm{~L}$ EGFR-TKI treatment the objectives were to describe the proportion of patients that received 2L and type of therapy started; the proportion of patients tested for T790M and were positive; of the patients who were T790M tested and who were not tested, what proportion received $2 \mathrm{~L}$ and type of therapy initiated.

\section{Data Collection}

The index date was defined as the first date on which a patient newly initiated a $1 \mathrm{G} / 2 \mathrm{G}$ EGFR-TKI as $1 \mathrm{~L}$ treatment for EGFRm locally advanced or metastatic NSCLC, and had to occur within a 3-year period from January 12015 through December 312017 (study entry window); patient data was abstracted through to last available medical record (data cut-off: 01 August 2019). Any data available from before or after the study index date through to the date of the medical record abstraction was subject to review. The study entry window for 1L EGFR TKI initiation was selected to balance the opportunity for maximal follow-up with the capture of recently prevailing patterns of care.

\section{Statistical Analyses}

The study aimed to include 235 patients from South Korea and 100 patients from Taiwan. Each participating physician was anticipated to contribute 15 to 20 patient records. All analyses were descriptive in nature and no statistical comparisons were made between patient data from the two countries. Study variables were summarized using univariate statistics, including mean, standard deviation, median and range for continuous variables and frequency distributions for categorical variables.

\section{Results}

\section{Physicians}

A total of 27 physicians participated in the South Korean study and 13 physicians in the Taiwan study. Their medical specialty was primarily medical/clinical oncologist (South Korea: 74\%; Taiwan: 54\%), followed by hematologist (South Korea: 26\%; Taiwan: 46\%). The median (range) number of years in practice was 20 (10-28) and 10 (5-20) years in South Korea and Taiwan, respectively.

Baseline Patient Demographics and Disease Characteristics

\section{South Korea}

From South Korea, 235 patients with EGFRm locally advanced or metastatic NSCLC were identified for inclusion in the study (Table 1). The majority of patients had a histologic diagnosis of adenocarcinoma (231; 98\%), median (range) age at index was $70(40-93)$ years, with 142 patients $(60 \%) \geq 65$ years of age; 149 patients $(63 \%)$ were female and, overall, 151 (64\%) never smokers. At initial NSCLC diagnosis, most patients had metastatic disease (stage IV) [29] (89\%), followed by early stage disease (stage IA, IB, IIA and IIB) [29] (8\%), limited regional (stage IIIA) [29] (2\%), locally advanced (stage IIIB) [29] $(2 \%)$, and unknown $(<1 \%)$. At the time of diagnosis with advanced or metastatic NSCLC, 148 patients $(63 \%)$ had an Eastern Cooperative Oncology Group Performance Status (ECOG PS) score of 0 or 1 . The majority of patients tested positive for Ex19del ( $\mathrm{n}=135$ [57\%]), 89 (38\%) tested positive for L858R mutation and 21 (9\%) tested positive for other mutations (both single and co-occurring mutations; Table 1). Patients were followed up from index date until last available medical record for a median duration of $23.7(0.1-56.7)$ months.

\section{Taiwan}

One hundred patients from Taiwan with EGFRm NSCLC receiving $1 \mathrm{~L} 1 \mathrm{G} / 2 \mathrm{G}$ EGFR TKI treatment were identified for inclusion (Table 1). All patients had a histologic diagnosis of adenocarcinoma. Median (range) age at index was 65 (36-94) years, with 48 patients (48\%) $\geq 65$ years of age, 66 patients $(66 \%)$ were female and 86 (86\%) never smokers. At initial NSCLC diagnosis, most patients had metastatic disease (stage IV) [29] (89\%), followed by limited regional (stage IIIA) (5\%) [29] early stage disease (stage IA, IB, IIA and IIB) (3\%), [29] and locally advanced (stage IIIB) [29] (3\%). At the time of diagnosis with advanced or metastatic NSCLC, 65 patients $(65 \%)$ had an ECOG PS score of 0 or 1. Overall, 44 patients (44\%) tested positive for the L858R mutation, followed by Ex 19del in 43 patients (43\%); eleven patients $(11 \%)$ tested positive for PD-L1 expression and 20 patients (20\%) were positive for uncommon EGFR mutations, in isolation or in combinations. Patients were followed up for a median duration of 22.1 (2.3-50.7) months.

\section{Incidence of CNS Metastases and LM Disease}

In the South Korean cohort, 69 patients $(29 \%)$ had CNS metastases at diagnosis of locally advanced or metastatic NSCLC, while 162 patients (69\%) had no CNS metastases on scans at this first diagnosis, and in 4 patients $(2 \%)$ presence or absence of CNS metastases were unknown. From the Taiwan cohort, at diagnosis of locally advanced or metastatic NSCLC, 25 patients (25\%) had CNS metastases, 72 patients $(72 \%)$ had no CNS metastases on scans at this first diagnosis, and in 3 patients $(3 \%)$ presence or absence of CNS metastases were unknown.

Two patients in each cohort (representing $<1 \%$ and $2 \%$ of the study populations from South Korea and Taiwan, respectively) had LM disease at advanced/ metastatic NSCLC diagnosis; at index 3 patients (1\%) in the South Korean cohort and 1 patient (1\%) in the Taiwan cohort had LM disease. Four patients $(2 \%)$ in the South Korean cohort and 5 patients $(5 \%)$ from the Taiwan cohort, who did not have LM disease at advanced/metastatic NSCLC diagnosis, subsequently developed LM disease. 
Table 1. Patient Demographics and Disease Characteristics

\begin{tabular}{|c|c|c|}
\hline Characteristic, $\mathrm{n}(\%)$ & $\begin{array}{l}\text { South Korean population } \\
\qquad \mathrm{N}=235\end{array}$ & $\begin{array}{l}\text { Taiwan population } \\
\qquad \mathrm{N}=100\end{array}$ \\
\hline Age at index date ${ }^{a}$, Median (Min, Max) & $70(40-93)$ & $65(36-94)$ \\
\hline \multicolumn{3}{|l|}{ Distribution, years } \\
\hline $31-50$ & $15(6)$ & $11(11)$ \\
\hline $51-65$ & $78(33)$ & $41(41)$ \\
\hline $66-75$ & $73(31)$ & $25(25)$ \\
\hline $75+$ & $69(29)$ & $23(23)$ \\
\hline \multicolumn{3}{|l|}{ Sex, n (\%) } \\
\hline Male & $86(37)$ & $34(34)$ \\
\hline Female & $149(63)$ & $66(66)$ \\
\hline \multicolumn{3}{|l|}{ Smoking status at initial NSCLC diagnosis } \\
\hline Current smoker & $19(8)$ & $5(5)$ \\
\hline Former smoker & $58(25)$ & $9(9)$ \\
\hline Never smoker & $151(64)$ & $86(86)$ \\
\hline Unknown & $7(3)$ & $0(0)$ \\
\hline \multicolumn{3}{|l|}{ Stage $^{\mathrm{b}}$ at initial NSCLC diagnosis } \\
\hline Early (Stage IA, IB, IIA, IIB) & $18(8)$ & $3(3)$ \\
\hline Limited Regional (Stage IIIA) & $4(2)$ & $5(3)$ \\
\hline Locally Advanced (Stage IIIB) & $4(2)$ & $3(3)$ \\
\hline Metastatic (Stage IV) & $208(89)$ & $89(89)$ \\
\hline Unknown & $1(<1)$ & $0(0)$ \\
\hline \multicolumn{3}{|l|}{ EGFR mutation type (tested positive) (c,d $^{\mathrm{c}}$} \\
\hline Exon 19 deletion & $135(57)$ & $43(43)$ \\
\hline L858R mutation & $89(38)$ & $44(44)$ \\
\hline Uncommon & $18(8)$ & $19(19)$ \\
\hline Exon20/T790M & $3(1)$ & $1(1)$ \\
\hline \multicolumn{3}{|l|}{ Other mutations (tested positive) ${ }^{\mathrm{c}}$} \\
\hline PD-L1 expression & $14(6)$ & $11(11)$ \\
\hline ALK rearrangement & $15(6)$ & 0 \\
\hline KRAS & 0 & 0 \\
\hline ROS-1 translocation & 0 & 0 \\
\hline BRAF mutation & 0 & 0 \\
\hline RET rearrangement & 0 & 0 \\
\hline HER 2 exon 20 insertion & 0 & 0 \\
\hline TP53 (any variant) & 0 & 0 \\
\hline None of the mutations listed above & $176(75)$ & $3(3)$ \\
\hline Unknown & $30(13)$ & $86(86)$ \\
\hline \multicolumn{3}{|c|}{ ECOG PS at first diagnosis of locally advanced/metastatic NSCLC } \\
\hline 0 & $78(33)$ & $19(19)$ \\
\hline 1 & $70(30)$ & $46(46)$ \\
\hline 2 & $10(4)$ & $8(8)$ \\
\hline 3 & $5(2)$ & $3(3)$ \\
\hline 4 & 0 & $0(0)$ \\
\hline ECOG not recorded at initial NSCLC diagnosis & $72(31)$ & $24(24)$ \\
\hline
\end{tabular}

ECOG PS, Eastern Cooperative Oncology Group performance status; EGFR, epidermal growth factor receptor; NSCLC, non-small cell lung cancer; andex date defined as first date on which a patient newly initiated a $1 \mathrm{G} / 2 \mathrm{G}$ EGFR TKI as $1 \mathrm{~L}$ treatment for EGFR-mutated locally advanced or metastatic NSCLC; ${ }^{\mathrm{b}} \mathrm{AJCC}$ TMN Classification of Lung Cancer ( $7^{\text {th }}$ edition); ${ }^{\mathrm{c}}$ Categories not mutually exclusive; column percentages may sum to greater than 100\%; 'Mutations other than del-19 or L858R, for example, L861Q, T790M, G719X, V769M, Moc31, exon 21, p.L861Q 
Table 2. Treatment Patterns among Patients Positive for EGFR Mutations During 1L, 2L and 3L Therapy

\begin{tabular}{|c|c|c|}
\hline & $\begin{array}{l}\text { South Korean population } \\
\qquad \mathrm{N}=235\end{array}$ & $\begin{array}{c}\text { Taiwan population } \\
\qquad \mathrm{N}=100\end{array}$ \\
\hline \multicolumn{3}{|l|}{ Regimen distribution in $1 \mathrm{~L}, \mathrm{n}(\%)$} \\
\hline Median (range) duration of $1 \mathrm{~L}$ treatment, months & $10.3(0.1-37.2)$ & $9.9(1.9-42.4)$ \\
\hline \multicolumn{3}{|l|}{ EGFR-TKI treatment } \\
\hline Erlotinib & $30(13)$ & $37(37)$ \\
\hline Gefitinib & $100(43)$ & $36(36)$ \\
\hline Afatinib & $105(45)$ & $27(27)$ \\
\hline Second-line treatment regimen, $\mathrm{n}(\%)$ & $(n=120)$ & $(\mathrm{n}=63)$ \\
\hline Median (range) duration of 2L treatment, months & $3.2(0.1-26.9)$ & $3.3(0.03-19.8)$ \\
\hline \multicolumn{3}{|l|}{ Chemotherapy only } \\
\hline Cisplatin + pemetrexed & $17(14)$ & $28(44)$ \\
\hline Carboplatin + pemetrexed & 0 & $5(8)$ \\
\hline Cisplatin + gemcitabine & $2(2)$ & $3(5)$ \\
\hline Pemetrexed & $49(41)$ & $3(3)$ \\
\hline Carboplatin + gemcitabine & $4(3)$ & $1(2)$ \\
\hline Bevacizumab + carboplatin + gemcitabine & 0 & $1(2)$ \\
\hline Gemcitabine + vincristine & $1(1)$ & 0 \\
\hline Gemcitabine & $1(1)$ & 0 \\
\hline Cisplatin + docetaxel + pemetrexed & 0 & $1(2)$ \\
\hline Docetaxel & $1(1)$ & 0 \\
\hline \multicolumn{3}{|l|}{ EGFR-TKI treatment } \\
\hline Osimertinib & $38(32)$ & $16(25)$ \\
\hline Afatinib & $2(2)$ & 0 \\
\hline Erlotinib & $1(1)$ & $1(2)$ \\
\hline \multicolumn{3}{|l|}{ EGFR-TKI + chemotherapy } \\
\hline Carboplatin + osimertinib + paclitaxel & 0 & $1(2)$ \\
\hline Carboplatin + osimertinib + pemetrexed & 0 & $1(2)$ \\
\hline Osimertinib + pemetrexed & 0 & $1(2)$ \\
\hline \multicolumn{3}{|l|}{ Immunotherapy } \\
\hline Cisplatin + pembrolizumab & 0 & $2(3)$ \\
\hline Pembrolizumab & $1(1)$ & 0 \\
\hline Nivolumab & $1(1)$ & 0 \\
\hline \multicolumn{3}{|l|}{ ROS1/ALK inhibitors } \\
\hline Crizotinib & $2(2)$ & 0 \\
\hline
\end{tabular}

\section{$1 L$ EGFR-TKI Treatment Patterns}

At diagnosis of locally advanced or metastatic NSCLC, all patients received a $1 \mathrm{~L} 1 \mathrm{G} / 2 \mathrm{G}$ EGFR-TKI as monotherapy (Table 2). In the South Korea cohort, $45 \%$ of patients received afatinib, $43 \%$ received gefitinib and $13 \%$ received erlotinib; the median duration of $1 \mathrm{~L}$ treatment was $10.3(0.1-37.2)$ months. In the Taiwan cohort, a similar proportion of patients received afatinib (27\%), erlotinib (37\%) or gefitinib (36\%) as their 1L EGFR TKI treatment; the median duration of $1 \mathrm{~L}$ treatment was 9.9 (1.9-42.4) months.

\section{$2 L$ Therapy after $1 L$ Treatment Progression}

In the South Korea cohort, $120 / 164$ patients $(73 \%)$ who experienced disease progression on 1L treatment received
2L therapy (Table 2). Fourteen patients (9\%) of the 164 with a progression event died before they received $2 \mathrm{~L}$. Pemetrexed was the most common 2L treatment received (49/120; 41\%), followed by osimertinib (38/120; 32\%), and cisplatin plus pemetrexed $(17 / 120 ; 14 \%$; Table 2$)$. The median (range) duration of $2 \mathrm{~L}$ treatment was 3.2 $(0.1,26.9)$ months.

Eighty-nine patients experienced disease progression on 1L treatment in the Taiwan cohort, of whom 63 (71\%) received a $2 \mathrm{~L}$ therapy (Table 2 ). Of the 89 patients who had disease progression 21 (24\%) died before receiving $2 \mathrm{~L}$ therapy. The most frequently received $2 \mathrm{~L}$ therapy was cisplatin plus pemetrexed in $28 / 63$ patients $(44 \%)$, followed by osimertinib monotherapy in $16 / 63$ patients (25\%). The median (range) duration of $2 \mathrm{~L}$ therapy was 
A

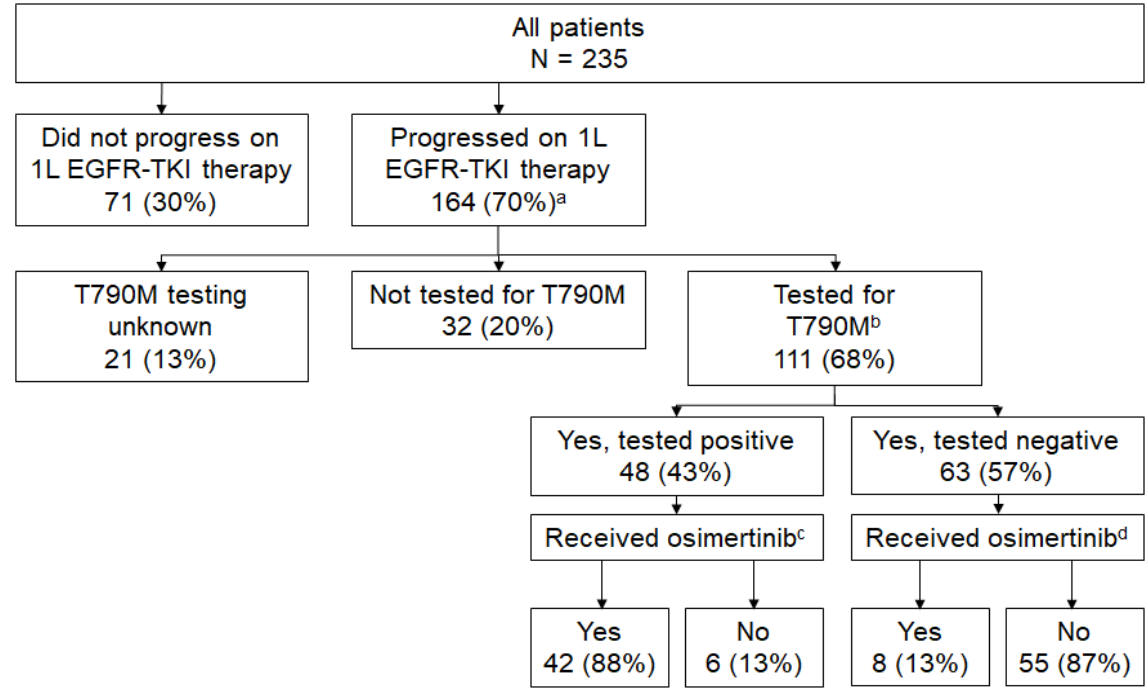

B

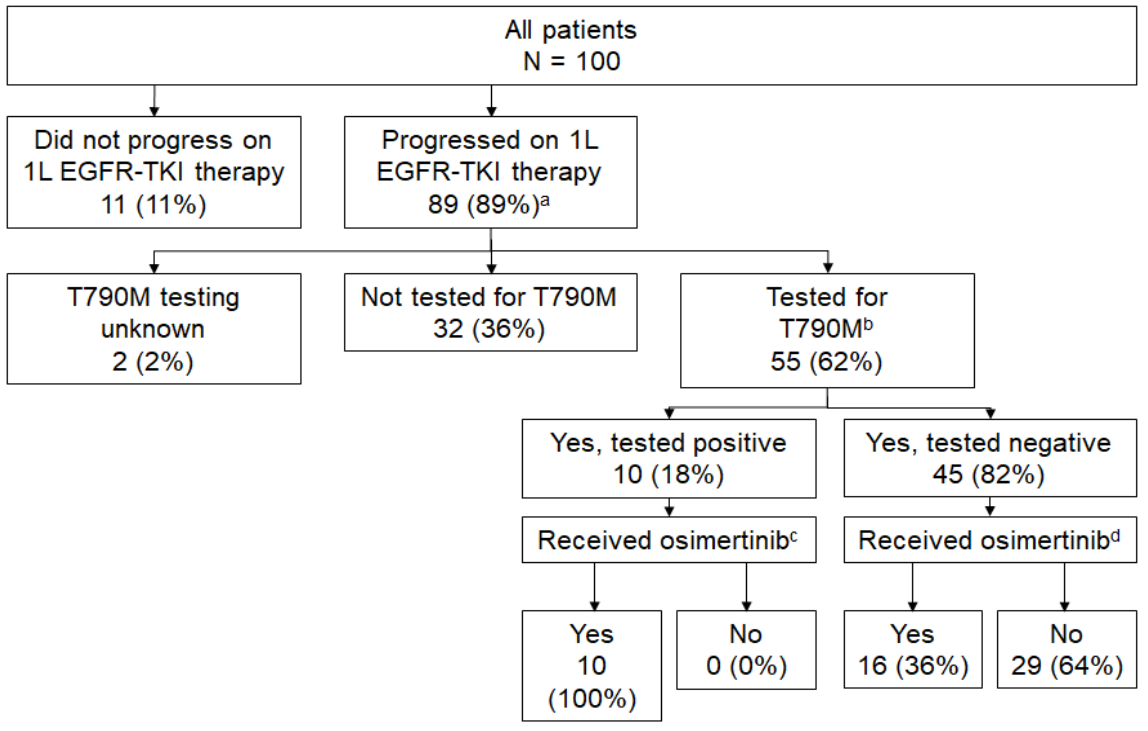

Figure 1. T790M Testing Performed and Outcomes in Patients with NSCLC Treated with a 1L EGFR-TKI A) South Korean cohort; B) Taiwan Cohort. A, ${ }^{a} 14 / 164$ (9\%) patients who progressed on 1L EGFR-TKI treatment died, prior to receiving $2 \mathrm{~L}$. ${ }^{\mathrm{b}}$ Calculated as the proportion of patients who progressed on $1 \mathrm{~L}$ EGFR-TKI treatment. Patients could have been tested at any point from initial NSCLC diagnosis to end of follow-up period. ${ }^{\circ}$ Calculated as the proportion of patients who tested positive for T790M, patients could have received osimertinib at second-line or later. ${ }^{\mathrm{d}}$ Calculated as the proportion of patients who tested negative for $T 790 \mathrm{M}$, patients could have received osimertinib at second-line or later. EGFR, epidermal growth factor receptor; NSCLC, non-small cell lung cancer; TKI, tyrosine kinase inhibitor. B, EGFR, epidermal growth factor receptor; NSCLC, non-small cell lung cancer; TKI, tyrosine kinase inhibitor. ${ }^{2} 21 / 89$ $(24 \%)$ patients who progressed on 1L EGFR-TKI treatment died, prior to receiving $2 \mathrm{~L}$. ${ }^{\mathrm{b}} \mathrm{Calculated}$ as the proportion of patients who progressed on 1L EGFR-TKI treatment. Patients could have been tested at any point from initial NSCLC diagnosis to end of follow-up period. ${ }^{\circ}$ Calculated as the proportion of patients who tested positive for T790M, patients could have received osimertinib at second-line or later. ${ }^{\mathrm{d} C a l c u l a t e d}$ as the proportion of patients who tested negative for T790M, patients could have received osimertinib at second-line or later. 


\section{$3.3(0.03-19.8)$ months.}

\section{T790M Mutation Testing}

Of the 164 patients who experienced disease progression on $1 \mathrm{~L}$ treatment in the South Korea cohort, 111 patients $(68 \%)$ received testing for $\mathrm{T} 790 \mathrm{M}$, with $48 / 111$ patients $(43 \%)$ whose tumors tested positive (Figure 1A); in addition, $47 / 71$ patients $(66 \%)$ who did not experience disease progression on $1 \mathrm{~L}$ treatment were tested for T790M. In the majority of patients, the test type was categorized as 'other' $(106 / 158 ; 67 \%)$, with the PNA Clamp ${ }^{\mathrm{TM}}$ EGFR mutation detection kit v2.0 most commonly used $(49 / 106 ; 46 \%)$. The test type was not known in $50 / 158$ patients $(32 \%)$. Of the 48 patients whose tumors tested positive for T790M, 42 (88\%) subsequently received osimertinib (Figure 1A). Of the 63 patients $(57 \%)$ whose tumors tested negative for T790M, 8 (13\%) received osimertinib at $2 \mathrm{~L}$ or later (Figure 1). Median time to next treatment in patients whose tumors were T790M tested was 16.4 months $(13.9,17.5)$ and 16.5 months $(12.2,22.5)$ in patients who were not tested.

In the Taiwan cohort, of the 89 patients who experienced disease progression on $1 \mathrm{~L}$ treatment, 55 patients $(62 \%)$ underwent T790M testing, with 10 patients (18\%) whose tumors tested T790M positive (Figure 1B); in addition, the tumors of 7 of the 11 patients (64\%) who did not experience disease progression on $1 \mathrm{~L}$ treatment were tested for T790M. Most patients had their T790M mutation status confirmed by test type categorized as 'other' $(46 / 62 ; 74 \%)$; the most common test type used in this category was the MassARRAY genotyping kit $(37 / 46 ; 80 \%)$. The test type was categorized as unknown for 5 patients $(8 \%)$. Of the 10 patients who had tumors that tested positive for $\mathrm{T} 790 \mathrm{M}$, all received osimertinib $2 \mathrm{~L}$ or later (Figure 1B). From the $45 / 55$ patients $(82 \%)$ with $1 \mathrm{~L}$ disease progression whose tumors tested negative for T790M, 16/45 (36\%) subsequently received regimens including osimertinib $2 \mathrm{~L}$ or later. Median time to next treatment in patients who were T790M tested was 12.6 months $(9.6,17.1)$ and 12.7 months $(9.9,42.3)$ in patients who were not tested.

\section{Osimertinib Treatment and Line of Treatment}

Overall, 54/235 patients (23\%) in the South Korea cohort and $27 / 100$ patients $(27 \%)$ in the Taiwan cohort received osimertinib at $2 \mathrm{~L}$ or later. The majority $(38 / 54$ [70\%] patients and 16/27 [59\%] for South Korea and Taiwan, respectively) received osimertinib monotherapy in the $2 \mathrm{~L}$ setting.

\section{Discussion}

This retrospective, non-interventional medical record review evaluated real-world treatment patterns and T790M testing practices in patients with EGFRm advanced/ metastatic NSCLC receiving $1 \mathrm{~L} 1 \mathrm{G} / 2 \mathrm{G}$ EGFR-TKIs in populations in South Korea and Taiwan.

The demographics of the patients eligible for inclusion in this analysis were generally similar to those observed in randomized, clinical trials of EGFRm NSCLC in Asian cohorts, with the exception of the high proportion of never smokers in the Taiwan cohort ( $86 \%$ vs $\sim 60 \%$ ) [30-31] and the older population in the South Korea cohort compared with Taiwan; the median age of patients from South Korea was 70 years ( $>60 \%$ aged $\geq 65$ years $)$ whereas in clinical trials, the median age of patients was up to 7 years younger [30, 32-33].

In the Taiwan cohort, $1 \mathrm{~L}$ afatinib, erlotinib and gefitinib were prescribed at similar frequencies. By contrast, in the South Korean cohort nearly half (45\%) of the patients received the second-generation EGFR-TKI afatinib as $1 \mathrm{~L}$ treatment, with a similar proportion $(43 \%)$ receiving gefitinib, while erlotinib was only prescribed to $13 \%$ of patients. This prescribing pattern, with a preference for gefitinib over erlotinib as the $1 \mathrm{~L}$ treatment, may reflect the different AE profiles of the two treatment and physician/ patient choice of treatment. In particular, higher rates of anorexia and skin rash have been reported with erlotinib compared with gefitinib, which may impact treatment choice, particularly in older patients and female patients who may be concerned about the cosmetic impact of skin reactions [32, 34-35]. These prescribing patterns may reflect the older and predominantly female patient population in the South Korean cohort. However, it would be expected that physicians/patients in Taiwan would have similar considerations, so the different prescribing patterns noted between countries may also be due to the small sample size of Taiwanese patients. In another real-world study which enrolled nearly 6000 patients with stage IIIB and IV NSCLC receiving EGFR-TKIs in Taiwan between 2011 to $2015,67 \%$ of patients received gefitinib, while $20 \%$ of patients received erlotinib [36], which is more in line with the relative proportions of gefitinib and erlotinib used in South Korean patients in our study. Also, in this larger Taiwanese study, there were more elderly ( $\geq 65$ years: $55 \%$ versus $50 \%$ ) and female patients $(66 \%$ vs $56 \%)$ in the gefitinib group compared with the erlotinib group [36].

Our study showed that $70 \%$ and $89 \%$ of patients in the South Korean and Taiwan cohorts, respectively, had disease progression during the study period and a considerable proportion of the patients who experienced disease progression ( $20 \%$ and $36 \%$, respectively) did not receive a test for the $\mathrm{T} 790 \mathrm{M}$ resistance mutation. Of patients with disease progression, the majority (67\% in South Korea and 70\% in Taiwan) did not receive any line of osimertinib. Osimertinib was prescribed off-label in patients who tested negative for T790M in both South Korea $(8 / 63 ; 13 \%)$ and Taiwan $(16 / 45 ; 36 \%)$. Although the reasons for why patients' tumors were not tested for T790M or did not receive 2L therapy were not recorded in the eDCF, this finding suggested a potential unmet need in disease management and treatment in these populations.

The number of patients in the Taiwan cohort with T790M-positive tumors was low $(18 \%$ vs $43 \%$ in the South Korean cohort), which is more similar to that observed in other real-world studies with Asian and non-Asian cohorts (approximately 30\%) [16-18] than in clinical trials (approximately 50\%) [15, 37]. It is worth 
noting that the incidence of uncommon/complex EGFR mutations (20\%) in the Taiwan cohort was slightly higher than rates seen in other studies $(12-16 \%)$ of Asian patient cohorts [38-39].

In both countries, approximately a quarter of patients had CNS metastases at diagnosis of locally advanced or metastatic NSCLC and a further $15 \%$ and $10 \%$ of patients, respectively, went on to develop CNS metastases during the study. CNS metastases frequently occur in patients with EGFRm NSCLC and are associated with poor outcomes [40]. In the 1L setting in the FLAURA study, osimertinib has been shown to reduce the risk of CNS progression by $52 \%$ versus comparator EGFR-TKIs (HR, $0.48 ; \mathrm{P}=0.014$ ) [21]. Early intervention with osimertinib could reduce the risk of CNS progression in patients with CNS metastases.

Limitations of the study included the retrospective nature of a chart review, meaning data were more likely to be missing, along with the potential for selection bias in patients included in the study. While all patients who met the inclusion criteria were included, patients who died early on in the study period may have been less likely to be included than those who were alive at data abstraction. Furthermore, it was not possible to determine why testing for T790M was not completed in all patients who had experienced disease progression. During the majority of this study, osimertinib was not approved or reimbursed in South Korea or Taiwan, which may have resulted in lower than expected T790M testing and treatment with $2 \mathrm{~L}$ osimertinib. Since the study was completed, treatment and testing patterns may have changed due to changes in $2 \mathrm{~L}$ osimertinib reimbursement status and the approval of osimertinib in the 1L setting. Finally, data were abstracted from medical records of 27 physicians in South Korea and 13 physicians in Taiwan, thus limiting the generalizability of treatment patterns across the countries as a whole.

In conclusion, our real-world study of treatment patterns and T790M testing practices in patients with advanced/metastatic EGFRm NSCLC receiving $1 \mathrm{~L}$ $1 \mathrm{G} / 2 \mathrm{G}$ EGFR TKI treatment indicated that a large proportion of patients in South Korea and Taiwan did not receive $2 \mathrm{~L}$ therapy after disease progression, highlighting the importance of $1 \mathrm{~L}$ treatment decisions. In addition, improvements in resistance mutation testing were needed, although $2 \mathrm{~L}$ therapy utilization was as per the recommendations for the majority of T790M-positive patients. These treatment patterns may have changed since study initiation as osimertinib received reimbursement status for 2L treatment in South Korea and Taiwan from December 2017 onwards, so follow-up studies are required.

\section{Acknowledgements}

The study was funded by AstraZeneca, Cambridge, UK, the manufacturer of osimertinib. Medical writing support for the development of this manuscript, under the direction of the authors, was provided by Alexandra Webster, MSc, of Ashfield MedComms (Witney,
UK), an Ashfield Health company, and was funded by AstraZeneca, Cambridge, UK in accordance with Good Publication Practice (GPP3) guidelines. The authors thank the investigators who participated in this study.

\section{Author Disclosures}

Young-Chul Kim has received research grants from AstraZeneca, Roche, and Boehringer Ingelheim. Keith L Davis is an employee of RTI Health Solutions. Saurabh P Nagar is an employee of RTI Health Solutions; and has received consulting fees from AstraZeneca. Aliki Taylor is an employee of AstraZeneca; reports ownership of stocks/ shares in AstraZeneca. Sung Yong Lee reports honoraria from AstraZeneca. Jin-Yuan Shih reports honoraria from AstraZeneca, Roche, Boehringer Ingelheim, Eli Lilly, Pfizer, Novartis, Merck Sharp \& Dohme, Chugai Pharma, Ono Pharmaceutical, and Bristol-Myers Squibb; and has received consulting fees from AstraZeneca, Roche, Boehringer Ingelheim, Eli Lilly, Pfizer, Novartis, Merck Sharp \& Dohme, Chugai Pharma, Ono Pharmaceutical, Takeda, CStone Pharmaceuticals, Janssen, and BristolMyers Squibb. Jae Cheol Lee, Jen-Yu Hung, Gee-Chen Chang, Seung Soo Yoo and Sheng-Hsiung Yang have no conflict of interest to report.

\section{References}

1. Zhang Y, Yuan J, Wang K, Fu X, Han X, Threapleton D, Yang $Z$, Mao C, Tang J. The prevalence of EGFR mutation in patients with non-small cell lung cancer: a systematic review and meta-analysis. Oncotarget. 2016 Oct 12;7(48):7898578993. https://doi.org/10.18632/oncotarget.12587

2. Midha A, Dearden S, McCormack R. EGFR mutation incidence in non-small-cell lung cancer of adenocarcinoma histology: a systematic review and global map by ethnicity (mutMapII). Am J Cancer Res. 2015;5(9):2892-2911.

3. Chantharasamee J, Poungvarin N, Danchaivijitr P, Techawatanawanna S. Clinical outcome of treatment of metastatic non-small cell lung cancer in patients harboring uncommon EGFR mutation. BMC Cancer. 201907 17;19(1):701. https://doi.org/10.1186/s12885-019-5913-9

4. Park E, Shim HS. Detection of targetable genetic alterations in Korean lung cancer patients: a comparison study of single-gene assays and targeted next-generation sequencing. Cancer Res Treat. 202004 15;52(2):543-551. https://doi. org/10.4143/crt.2019.305

5. Lee SH, Kim WS, Choi YD, Seo JW, Han JH, Kim MJ, Kim L, Lee GK, Lee CH, Oh MH, Kim GY, Sung SH, Lee KY, Chang SH, Rho MS, Kim HK, Jung SH, Jang SJ. Analysis of mutations in epidermal growth factor receptor gene in Korean patients with non-small cell lung cancer: summary of a nationwide survey. J Pathol Transl Med. 2015 Oct 13;49(6):481-488. https://doi.org/10.4132/jptm.2015.09.14

6. Sun P, Seol H, Lee HJ, Yoo SB, Kim H, Xu X, Jheon S, Lee $\mathrm{C}$, Lee J, Chung J. High incidence of EGFR mutations in Korean men smokers with no intratumoral heterogeneity of lung adenocarcinomas: correlation with histologic subtypes, EGFR/TTF-1 expressions, and clinical features. J Thorac Oncol. 2012 02;7(2):323-330. https://doi.org/10.1097/ jto.0b013e3182381515

7. Yatabe Y, Kerr KM, Utomo A, Rajadurai P, Tran VK, Du X, Chou T, Enriquez MLD, Lee GK, Iqbal J, Shuangshoti S, Chung J, Hagiwara K, Liang Z, Normanno N, Park K, Toyooka S, Tsai C, Waring P, Zhang L, McCormack 
R, Ratcliffe M, Itoh Y, Sugeno M, Mok T. EGFR mutation testing practices within the Asia Pacific region: results of a multicenter diagnostic survey. J Thorac Oncol. 2015 03;10(3):438-445. https://doi.org/10.1097/ jto.0000000000000422

8. Cheng P, Cheng Y. Correlation between familial cancer history and epidermal growth factor receptor mutations in Taiwanese never smokers with non-small cell lung cancer: a case-control study. J Thorac Dis. 2015;7(3):281-287. https:// doi.org/10.3978/j.issn.2072-1439.2015.02.03

9. Shigematsu H, Lin L, Takahashi T, Nomura M, Suzuki M, Wistuba II, Fong KM, Lee H, Toyooka S, Shimizu N, Fujisawa T, Feng Z, Roth JA, Herz J, Minna JD, Gazdar AF. Clinical and biological features associated with epidermal growth factor receptor gene mutations in lung cancers. J Natl Cancer Inst. 200503 01;97(5):339-346. https://doi. org/10.1093/jnci/dji055

10. Hanna N, Johnson D, Temin S, Baker S, Brahmer J, Ellis PM, Giaccone G, Hesketh PJ, Jaiyesimi I, Leighl NB, Riely GJ, Schiller JH, Schneider BJ, Smith TJ, Tashbar J, Biermann WA, Masters G. Systemic therapy for stage IV non-small-cell lung cancer: American Society of Clinical Oncology Clinical Practice Guideline Update. J Clin Oncol. 2017 Oct 20;35(30):3484-3515. https://doi.org/10.1200/ jco.2017.74.6065

11. Novello S, Barlesi F, Califano R, Cufer T, Ekman S, Levra MG, Kerr K, Popat S, Reck M, Senan S, Simo G, Vansteenkiste J, Peters S. Metastatic non-small-cell lung cancer: ESMO Clinical Practice Guidelines for diagnosis, treatment and follow-up. Ann Oncol. 2016 09;27:v1-v27. https://doi.org/10.1093/annonc/mdw326

12. Oxnard GR, Arcila ME, Sima CS, Riely GJ, Chmielecki J, Kris MG, Pao W, Ladanyi M, Miller VA. Acquired resistance to EGFR tyrosine kinase inhibitors in EGFR-mutant lung cancer: distinct natural history of patients with tumors harboring the T790M mutation. Clin Cancer Res. $2010 \mathrm{Dec}$ 06;17(6):1616-1622. https://doi.org/10.1158/1078-0432. ccr-10-2692

13. Yu HA, Arcila ME, Rekhtman N, Sima CS, Zakowski MF, Pao W, Kris MG, Miller VA, Ladanyi M, Riely GJ. Analysis of tumor specimens at the time of acquired resistance to EGFR-TKI therapy in 155 patients with EGFR-mutant lung cancers. Clin Cancer Res. 201303 07;19(8):2240-2247. https://doi.org/10.1158/1078-0432.ccr-12-2246

14. Ho G, Chai C, Alip A, Wahid MIA, Abdullah MM, Foo Y, How S, Zaatar A, Lam K, Leong K, Low J, Yusof MM, Lee EC, Toh Y, Liam C. Real-world experience of first-line afatinib in patients with EGFR-mutant advanced NSCLC: a multicenter observational study. BMC Cancer. 201909 09;19(1):896. https://doi.org/10.1186/s12885-019-6107-1

15. Wang Z, Ren S, Li W, Gao G. Frequency of the acquired resistant mutation T790 $\mathrm{M}$ in non-small cell lung cancer patients with active exon 19Del and exon 21 L858R: a systematic review and meta-analysis. BMC Cancer. 201802 06;18(1): 148. https://doi.org/10.1186/s12885-018-4075-5

16. Seto T, Nogami N, Yamamoto N, Atagi S, Tashiro N, Yoshimura Y, Yabuki Y, Saka H. Real-world EGFR T790M testing in advanced non-small-cell lung cancer: a prospective observational study in Japan. Oncol Ther. 201808 28;6(2):203-215. https://doi.org/10.1007/s40487018-0064-8

17. Nadler E, Pavilack M, Espirito JL, Clark J, Fernandes A. Observational study of treatment patterns in patients with epidermal growth factor receptor (EGFR) mutation-positive non-small cell lung cancer after first-line EGFR-tyrosine kinase inhibitors. Adv Ther. 202001 18;37(2):946-954. https://doi.org/10.1007/s12325-020-01221-4
18. Chiang AC, Fernandes AW, Pavilack M, Wu JW, Laliberté F, Duh MS, Chehab N, Subramanian J. EGFR mutation testing and treatment decisions in patients progressing on first- or second-generation epidermal growth factor receptor tyrosine kinase inhibitors. BMC Cancer. 202004 28;20(1): 356. https://doi.org/10.1186/s12885-020-06826-0

19. Cross DA, Ashton SE, Ghiorghiu S, Eberlein C, Nebhan CA, Spitzler PJ, Orme JP, Finlay MRV, Ward RA, Mellor MJ, Hughes G, Rahi A, Jacobs VN, Brewer MR, Ichihara E, Sun J, Jin H, Ballard P, Al-Kadhimi K, Rowlinson R, Klinowska T, Richmond GH, Cantarini M, Kim D, Ranson MR, Pao W. AZD9291, an irreversible EGFR TKI, overcomes T790Mmediated resistance to EGFR inhibitors in lung cancer. Cancer Discov. 201406 03;4(9):1046-1061. https://doi. org/10.1158/2159-8290.cd-14-0337

20. Soria J, Ohe Y, Vansteenkiste J, Reungwetwattana T, Chewaskulyong B, Lee KH, Dechaphunkul A, Imamura F, Nogami N, Kurata T, Okamoto I, Zhou C, Cho BC, Cheng Y, Cho EK, Voon PJ, Planchard D, Su W, Gray JE, Lee S, Hodge R, Marotti M, Rukazenkov Y, Ramalingam SS. Osimertinib in untreated EGFR-mutated advanced non-small-cell lung cancer. N Engl J Med. 201801 11;378(2):113-125. https:// doi.org/10.1056/nejmoa1713137

21. Reungwetwattana T, Nakagawa K, Cho BC, Cobo M, Cho EK, Bertolini A, Bohnet S, Zhou C, Lee KH, Nogami N, Okamoto I, Leighl N, Hodge R, McKeown A, Brown AP, Rukazenkov Y, Ramalingam SS, Vansteenkiste J. CNS response to osimertinib versus standard epidermal growth factor receptor tyrosine kinase inhibitors in patients with untreated EGFR-mutated advanced non-small-cell lung cancer. J Clin Oncol. 2018 Nov 20;36(33):3290-3297. https://doi.org/10.1200/jco.2018.78.3118

22. Ramalingam SS, Vansteenkiste J, Planchard D, Cho BC, Gray JE, Ohe Y, Zhou C, Reungwetwattana T, Cheng Y, Chewaskulyong B, Shah R, Cobo M, Lee KH, Cheema P, Tiseo M, John T, Lin M, Imamura F, Kurata T, Todd A, Hodge R, Saggese M, Rukazenkov Y, Soria J. Overall survival with osimertinib in untreated, EGFR-mutated advanced NSCLC. N Engl J Med. 202001 02;382(1):41-50. https://doi.org/10.1056/nejmoa1913662

23. Chu M. Lung cancer therapy Tagrisso's price cut by $96 \%$ : Korea Biomedical Review; 2017. Available from: http://www.koreabiomed.com/news/articleView. $\mathrm{html}$ ?idxno=2024.

24. Tagrisso approved in China as first-in-class treatment for EGFR T790M mutation-positive metastatic non-small cell lung cancer: AstraZeneca; 2017. Available from: https:// www.astrazeneca.com/media-centre/press-releases/2017/ tagrisso-approved-in-china-as-first-in-class-treatment-foregfr-t790m-mutation-positive-metastatic-non-small-celllung-cancer-27032017.html.

25. Wu S, Chiang C, Liu C, Wang C, Su P, Hsia T, Shih J, Chang G. An observational study of acquired EGFR T790M-dependent resistance to EGFR-TKI treatment in lung adenocarcinoma patients in Taiwan. Front Oncol. 2020 09 04;10:1481. https://doi.org/10.3389/fonc.2020.01481

26. Wu Y, Planchard D, Lu S, Sun H, Yamamoto N, Kim D, Tan D, Yang J, Azrif M, Mitsudomi T, Park K, Soo R, Chang J, Alip A, Peters S, Douillard J. Pan-Asian adapted Clinical Practice Guidelines for the management of patients with metastatic non-small-cell lung cancer: a CSCO-ESMO initiative endorsed by JSMO, KSMO, MOS, SSO and TOS. Ann Oncol. 2019 02;30(2):171-210. https://doi.org/10.1093/ annonc/mdy554

27. US Food \& Drug Administration. TAGRISSO $®$ (osimertinib). Highlights of Prescribing Information. 2018. Available from: https://www.accessdata.fda.gov/drugsatfda_docs/ 
label/2018/208065s008lbl.pdf.

28. European Medicines Agency. TAGRISSO ${ }^{\text {TM }}$ (osimertinib) Summary of Product Characteristics. 2018. Available from: https://www.ema.europa.eu/en/documents/productinformation/tagrisso-epar-product-information_en.pdf.

29. Edge S, Byrd D, Compton C, Fritz A, Greene F, Trotti A, et al. AJCC Cancer Staging Handbook. $7^{\text {th }}$ ed. New York, NY: Springer; 2010 XIX, 718. ISBN: 978-0-387-88442-4

30. Cho BC, Chewaskulyong B, Lee KH, Dechaphunkul A, Sriuranpong V, Imamura F, Nogami N, Kurata T, Okamoto I, Zhou C, Cheng Y, Cho EK, Voon PJ, Lee J, Mann H, Saggese M, Reungwetwattana T, Ramalingam SS, Ohe Y. Osimertinib versus standard of care EGFR TKI as first-line treatment in patients with EGFRm advanced NSCLC: FLAURA Asian Subset. J Thorac Oncol. 2019 01;14(1):99-106. https://doi. org/10.1016/j.jtho.2018.09.004

31. Perng R, Yang C, Chen Y, Chang G, Lin M, Hsieh R, Chu N, Lai R, Su W, Tsao C, Hsia T, Chen H, Chen C, Huang M, Wang J, Ho M, Chung C, Yu C, Chang W, Kuo H, Yu C, Lin Z, Kao W. High efficacy of erlotinib in Taiwanese NSCLC patients in an expanded access program study previously treated with chemotherapy. Lung Cancer. 2008 Oct;62(1):7884. https://doi.org/10.1016/j.lungcan.2008.02.023

32. Uhm JE, Park B, Ahn M, Lee J, Ahn JS, Kim SW, Kim H, Lee JS, Kang JH, Cho JY, Song HS, Park SH, Sohn CH, Shin SW, Choi JH, Park K. Erlotinib monotherapy for stage IIIB/IV non-small cell lung cancer: a multicenter trial by the Korean Cancer Study Group. J Thorac Oncol. 2009 09;4(9):11361143. https://doi.org/10.1097/jto.0b013e3181b270a7

33. Mok T, Wu Y, Au JS, Zhou C, Zhang L, Perng R, Park K. Efficacy and safety of erlotinib in 1242 East/South-East Asian patients with advanced non-small cell lung cancer. J Thorac Oncol. 2010 Oct;5(10):1609-1615. https://doi. org/10.1097/jto.0b013e3181e15d55

34. Kim Y, Lee S, Ahn JS, Ahn M, Park K, Sun J. Efficacy and safety of afatinib for EGFR-mutant non-small cell lung cancer, compared with gefitinib or erlotinib. Cancer Res Treat. 201904 15;51(2):502-509. https://doi.org/10.4143/ crt.2018.117

35. Yang Z, Hackshaw A, Feng Q, Fu X, Zhang Y, Mao C, Tang J. Comparison of gefitinib, erlotinib and afatinib in non-small cell lung cancer: a meta-analysis. Int J Cancer. 201703 27;140(12):2805-2819. https://doi.org/10.1002/ijc.30691

36. Hsieh Y, Fang W, Lo Y, Chen Y, Chien L. Comparing the effectiveness of different EGFR-TKIs in patients with EGFR mutant non-small-cell lung cancer: a retrospective cohort study in Taiwan. Int J Cancer. 202001 07;147(4):1107-1116. https://doi.org/10.1002/ijc.32841

37. John T, Akamatsu H, Delmonte A, Su W, Lee JS, Chang G, Huang X, Jenkins S, Wu Y. EGFR mutation analysis for prospective patient selection in AURA3 phase III trial of osimertinib versus platinum-pemetrexed in patients with EGFR T790M-positive advanced non-small-cell lung cancer. Lung Cancer. 2018 Dec;126:133-138. https://doi. org/10.1016/j.lungcan.2018.10.027

38. Tu H, Ke E, Yang J, Sun Y, Yan H, Zheng M, Bai X, Wang Z, Su J, Chen Z, Zhang X, Dong Z, Wu S, Jiang B, Chen H, Wang B, Xu C, Zhou Q, Mei P, Luo D, Zhong W, Yang $\mathrm{X}, \mathrm{Wu}$ Y. A comprehensive review of uncommon EGFR mutations in patients with non-small cell lung cancer. Lung Cancer. 2017 Dec;114:96-102. https://doi.org/10.1016/j. lungcan.2017.11.005

39. Ahn B, Loong H, Chan O, Lee M, Olsen S, Cho B, et al. Prevalence of uncommon epidermal growth factor receptor (EGFR) alterations detected in circulating tumor DNA (ctDNA) of non-small cell lung cancer (NSCLC) patients from East Asia. J Clin Oncol. 2020;38(15_suppl):e21608-e. 40. Bhatt VR, D'Souza SP, Smith LM, Cushman-Vokoun AM, Noronha V, Verma V, Joshi A, Chougule A, Jambhekar N, Kessinger A, Marr A, Patil V, Banavali SD, Ganti AK, Prabhash K. Epidermal growth factor receptor mutational status and brain metastases in non-small-cell lung cancer. J Glob Oncol. 2017 06;3(3):208-217. https://doi.org/10.1200/ jgo.2016.003392

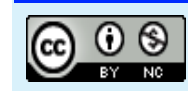

This work is licensed under a Creative Commons AttributionNon Commercial 4.0 International License. 